\title{
Stroke unit care in germany: the german stroke registers study group (ADSR)
}

\author{
Steffi Hillmann ${ }^{1 *}$, Silke Wiedmann ${ }^{1,2}$, Viktoria Rücker ${ }^{1}$, Klaus Berger $^{3}$, Darius Nabavi ${ }^{4}$, Ingo Bruder ${ }^{5}$, \\ Hans-Christian Koennecke ${ }^{6}$, Günter Seidel ${ }^{7}$, Björn Misselwitz ${ }^{8}$, Alfred Janssen ${ }^{9}$, Christoph Burmeister ${ }^{10}$, \\ Christine Matthis $^{11}$, Otto Busse ${ }^{12}$, Peter Hermanek ${ }^{13}$, Peter Ulrich Heuschmann ${ }^{1,2,14}$, on behalf of the German Stroke \\ Register Study Group (ADSR)
}

\begin{abstract}
Background: Factors influencing access to stroke unit (SU) care and data on quality of SU care in Germany are scarce. We investigated characteristics of patients directly admitted to a SU as well as patient-related and structural factors influencing adherence to predefined indicators of quality of acute stroke care across hospitals providing SU care.

Methods: Data were derived from the German Stroke Registers Study Group (ADSR), a voluntary network of 9 regional registers for monitoring quality of acute stroke care in Germany. Multivariable logistic regression analyses were performed to investigate characteristics influencing direct admission to SU. Generalized Linear Mixed Models (GLMM) were used to estimate the influence of structural hospital characteristics (percentage of patients admitted to SU, year of SU-certification, and number of stroke and TIA patients treated per year) on adherence to predefined quality indicators.

Results: In 2012 180,887 patients were treated in 255 hospitals providing certified SU care participating within the ADSR were included in the analysis; of those $82.4 \%$ were directly admitted to a SU. Ischemic stroke patients without disturbances of consciousness ( $p<.0001)$, an interval onset to admission time $\leq 3 \mathrm{~h}(p<.0001)$, and weekend admission $(p<.0001)$ were more likely to be directly admitted to a SU. A higher proportion of quality indicators within predefined target ranges were achieved in hospitals with a higher proportion of SU admission $(p=0.0002)$. Quality of stroke care could be maintained even if certification was several years ago.
\end{abstract}

Conclusions: Differences in demographical and clinical characteristics regarding the probability of SU admission were observed. The influence of structural characteristics on adherence to evidence-based quality indicators was low.

Keywords: Stroke unit care, Quality of health care, Quality indicators, Stroke register

\section{Background}

Overwhelming evidence from RCTs showed efficacy of stroke unit (SU) care [1] with data from RCTs being replicated in routine care in different countries and different SU settings [2-5]. In German SUs, specific focus is given to management and treatment of patients in the hyper acute phase, including multimodal monitoring of vital functions, rapid diagnosis, and early initiation of secondary prevention [6]. Independent certification of

\footnotetext{
* Correspondence: steffi.hillmann@uni-wuerzburg.de

${ }^{1}$ Institute of Clinical Epidemiology and Biometry (ICE-B) Würzburg,

Josef-Schneider-Str. 2 / D7, 97080 Würzburg, Germany

Full list of author information is available at the end of the article
}

SUs is performed mainly by the German Stroke Society (DSG) and the German Stroke Foundation (SDSH) [7]. Furthermore, stroke units are certified according to regional criteria of the federal states [8]. However, not all patients treated at hospitals providing $\mathrm{SU}$ care were admitted to SU. Available data on SU care in Germany are mainly based on routine data $[9,10]$ estimating for example that about $56.9 \%$ of all ischemic stroke (IS) patients in 2012 were admitted to a hospital with a specialized SU care in Germany [9]. However, routine data do not include detailed clinical relevant information such as stroke severity and comorbidities. Thus, it is currently unclear, if the demographic and clinical 
characteristics influence direct access of stroke patients to a SU. Furthermore, previous studies did not investigate variations in quality of stroke care by SU structures in Germany. Thus, it is unclear to what extent structural characteristics of the respective hospitals, such as certification procedures or percentage of stroke patients admitted to a $\mathrm{SU}$, might influence quality of care provided. Therefore, we investigated the influence of demographic and clinical characteristics of patients on direct admission to a SU as well as the influence of the structural characteristics on adherence to evidencebased quality indicators among hospitals providing SU care in Germany.

\section{Methods}

The german stroke registers study group (ADSR)

Data were derived from the German Stroke Registers Study Group (ADSR), a voluntary network of 9 regional registers (Bavaria, Baden-Württemberg, Berlin, Hamburg, Hesse, North Rhine, Northwest Germany, RhinelandPalatinate, and Schleswig-Holstein), which was founded in 1999 for monitoring quality of acute stroke care in Germany [11]. Data are collected mainly electronically, with predefined completeness and plausibility checks, by the respective quality assurance projects [12]. For example: date of ever treatment must be after the date of admission. Only plausible datasets were evaluated and sent to the data-pooling center. Each regional stroke register sends the complete data set in regular intervals to the data-pooling center (University of Würzburg, 2011-2015) [11]. Participation within a regional register of the ADSR is mandatory for all SUs in Germany certified according to the criteria of the DSG and the SDSH (see below) as well as for all hospitals in several regions [12].

\section{Stroke unit definition}

SUs were certified according to criteria of the German Stroke Society (DSG) and the German Stroke Foundation (SDSH) [13] and supported by the LGA InterCert [8]. SUs certified according to these criteria are distinguished into regional SUs and supra-regional SUs, depending on equipment and expertise [6]. Regional SUs have to treat at least 250 patients per year in at least 4 beds [14]. Supra-regional SUs have further demands on structural and procedural requirements [13, 14]. For example, interventional neuroradiology and neurosurgery and all relevant therapeutic and diagnostic facilities for stroke diagnosis, treatment, and management have to be available [6]. Additionally, a minimum of 450 patients per year treated in at least 6 monitoring beds are essential for certification of supra-regional SUs [14]. The minimum number of stroke patients per year was increased up to at least 500 in 2012 [13]. Beside these criteria, certification procedures by the local government of some federal states are also applied (i.e. BadenWürttemberg).

\section{Hospital characteristics}

Analyses were restricted to hospitals with a certified SU, according to criteria of the DSG, the SDSH or to regional criteria by the federal states that provided complete information regarding the admitting department. Investigated structural characterisis of participating hospitals providing SU care included: percentage of patients directly admitted to a SU (SU/general ward/intensive care unit/other), percentage of patients admitted directly to a SU $(<60 \%, 60-80 \%,>80 \%)$, year of first certification of the respective SU (2000-2002, 2003-2005, 2006-2008, 2009-2012), and number of stroke and Transient Ischemic Attack (TIA) patients treated per year $(<250,250-500,>500-750,>750)$.

\section{Quality Indicators}

A set of evidence based patient-oriented quality indicators was defined to measure quality of acute stroke care in participating hospitals. A standardized process was initiated for developing a set of evidence based quality indicators between 2003 and 2006 [11]. The process contained a systematic literature review, external independent validation and the conduction of a prospective pilot study [11]. The quality indicator set is updated on a regular basis every 2-3 years [15]. Target values of quality indicators were defined to indicate good quality of stroke care based on distribution within the data, national recommendations and expert consensus by the working group [15]. For the present analysis, the following set of 11 patient-oriented QIs with defined target values were used with definitions published previously [12]: early antithrombotic therapy; antithrombotic therapy - secondary prevention; anticoagulant therapy; brain imaging in patients with suspected strokes; vascular imaging in IS and TIA; screening for dysphagia; early rehabilitation - physiotherapy/occupational therapy; early rehabilitation - speech therapy; early mobilization; patients who arrived at the hospital within two hours from symptom onset and received brain imaging within one hour; early systemic thrombolytic therapy in eligible patients.

\section{Achievement of quality indicators}

Achievement of QIs was defined by reaching previously defined target values [12]. The proportion of achieved QIs was calculated by the number of QIs fulfilled in patients divided by the number of QIs that a patient could have fulfilled, according to the defined eligibility criteria of the respective QI. 


\section{Statistical analysis}

The following regional stroke audits were included in the present analyses: Hesse, Bavaria, Northwest Germany, Baden-Württemberg, North Rhine and the Berlin Stroke Register. Three regional stroke audits (Hamburg, Rhineland-Palatinate, and Schleswig-Holstein) were excluded because of missing or not comparable information on SU admission. Detailed descriptive and univariate analyses were performed to describe the demographic and clinical characteristics of the patients. Multivariable logistic regression analyses were performed to estimate the characteristics of ischemic stroke patients being admitted to a SU including: age (age group: $\leq 64 \mathrm{y}$, $\geq 65 \mathrm{y}$ and $\leq 74 \mathrm{y}, \geq 75 \mathrm{y}$ and $\leq 84 \mathrm{y}, \geq 85 \mathrm{y}$ ); sex; comorbidities (atrial fibrillation, diabetes mellitus, hypertension, previous stroke, hyperlipidemia); time from onset to admission ( $\leq 2 \mathrm{~h},>2-3 \mathrm{~h},>3-6 \mathrm{~h},>6-24 \mathrm{~h},>24 \mathrm{~h}-48 \mathrm{~h},>48 \mathrm{~h}$, unknown); NIHSS $(\leq 3,>4-15, \geq 15)$ [16]; and day of admission (weekday, weekend). Analyses were adjusted for regional audits. The association between hospital characteristics and the achievement of given target values to a defined set of evidence based quality indicators was assessed by Generalized Linear Mixed Models (GLMM). GLMM was used to estimate the $\mathrm{p}$-values and regression coefficients for the differences in the percentage of fulfilled quality indicators regarding the structure of the hospital (percentage of patients being admitted to a SU, year of certification of the respective $\mathrm{SU}$, and the number of stroke and TIA patients treated per year) and individual characteristics (age [categories], sex, stroke classification [ischemic stroke (IS), intracerebral hemorrhage ( $\mathrm{ICH})$, Transient Ischemic Attack (TIA), other], day of admission [weekday/weekend], and NIHSS on admission [categories]). The variable hospital was added as a random effect to model the correlations within the hospitals. Analyses were restricted to patients without missing values in the respective variables. The number of missing values ranged from $0.1 \%$ in age to $3.8 \%$ in NIHSS. Regarding the variables "interval onset to admission" and "day of admission", no comparable information was provided in one regional stroke register. Therefore, we performed a sensitivity analysis for the multivariable logistic regression analysis including all patients with missing information as own category. Statistical significance was determined at an alpha level of 0.05 . Statistical analyses were performed using the SAS 9.3 Software Package, SAS Institute Inc., Cary, NC, USA.

\section{Ethics}

The data pooling was approved by the ethics committee of the Charité-Universitätsmedizin Berlin (EA4/043/10) and is registered by the University of Würzburg (214/ 11). The identity of the individual patients was completely anonymous. Therefore, no specific informed consent was obtained by patients. The investigators who performed the data analyzes were blinded to hospital identities. These identities are only known by the coordinating center of the respective regional stroke registers [11].

\section{Results}

In $2012,180,887$ patients were included in the analysis from 255 hospitals providing certified SU care: of those, 149,001 patients have been directly admitted to SUs (82.4\%) The range of SU admission between the regional stroke audits was $77.9 \%-84.6 \%$. Median age of all patients was 74 years (IQR 64-82), 49.1\% were women. $66.4 \%$ had an (IS), 6.3\% had an intracerebral hemorrhage (ICH), 25.9\% had a transient ischemic attack (TIA), and $1.4 \%$ of strokes were undefined or subarachnoid hemorrhage. Demographical and clinical characteristics of all patients treated in hospitals with a certified SU by direct SU admission are provided in Table 1. The proportion of patients receiving thrombolysis therapy without admission on a SU was relatively high (10.9\%). This was due to the high number of thrombolysis therapy at Intensive Care Units (data not shown).

IS patients admitted on weekends $(p<.0001)$, with an interval-onset-admission time less than $3 \mathrm{~h}(p<.0001)$, with hypertension $(p<.0001)$, and hyperlipidemia $(p<.0001)$ are more likely, and patients with a previous stroke (0.0055) were less likely to be admitted directly to a SU. Contrary, patients with a severe stroke (NIHSS >15) had a lower probability of being admitted to a SU $(p<.0001)$ (Table 2). Results remained stable in a sensitivity analysis including all stroke subtypes, except for age. Patients younger than 85 years were more likely to be admitted on a SU $(p=0.0031)$. An additional sensitivity analysis based on all data including missing information as separate categories showed no substantial differences (data not shown).

\section{Quality indicators}

Results of achieved QIs by structural and individual factors are presented in Table 3. In hospitals with a SU, overall a mean of 93.7\% (SD 13.3) of the QIs were within the predefined target ranges. The proportion of patients admitted to SUs $(p=0.0002)$ had a significant impact on the achievement of quality indicators, whereas year of certification $(p=0.3014)$ and number of treated patients $(p=0.7238)$ showed no significant impact. Results remained stable in a sensitivity analysis stratifying by admission on a SU (Additional file 1: Table S1).

\section{Discussion}

Demographic and clinical factors influencing admission to a SU were identified in a large sample of hospitals across Germany. Results of our study show that patients admitted to SUs have milder strokes, suffer more from high blood pressure or hyperlipidemia, and are admitted earlier after stroke onset. A higher proportion of quality 
Table 1 Demographic and clinical characteristics of the patients

\begin{tabular}{|c|c|c|c|c|}
\hline & \multirow[t]{2}{*}{ Hospital with certified SU } & \multicolumn{2}{|c|}{ Admission on a SU } & \multirow[t]{2}{*}{$P$-value } \\
\hline & & Yes & No & \\
\hline No of centers & 255 & & & \\
\hline No of patients, n & 180,887 & 149,001 & 31,886 & \\
\hline Age, y & & & & $<.0001$ \\
\hline Mean (SD) & $72.0(13.4)$ & $72.1(13.3)$ & $71.6(14.0)$ & \\
\hline Median (IQR) & $74(64-82)$ & $74(64-82)$ & $74(63-82)$ & \\
\hline Age categories, y, \% & & & & $<.0001$ \\
\hline$<65$ & 25.8 & 25.4 & 27.3 & \\
\hline $65-74$ & 24.6 & 24.8 & 23.9 & \\
\hline $75-84$ & 32.6 & 32.8 & 31.5 & \\
\hline$\geq 85$ & 17.0 & 16.9 & 17.3 & \\
\hline Stroke subtype, \% & & & & $<.0001$ \\
\hline IS & 66.4 & 67.5 & 61.5 & \\
\hline $\mathrm{ICH}$ & 6.3 & 4.9 & 13.0 & \\
\hline TIA & 25.9 & 26.7 & 22.2 & \\
\hline other (unclassified, SAH) & 1.4 & 0.9 & 3.3 & \\
\hline Women, \% & 49.1 & 48.9 & 50.4 & $<.0001$ \\
\hline \multicolumn{5}{|l|}{ Comorbidities, \% } \\
\hline Atrial fibrillation & 25.8 & 26.0 & 24.7 & $<.0001$ \\
\hline Diabetes mellitus & 26.5 & 26.8 & 25.2 & $<.0001$ \\
\hline Hypertension & 82.6 & 83.2 & 79.5 & $<.0001$ \\
\hline Previous stroke & 24.6 & 24.9 & 23.1 & $<.0001$ \\
\hline Hyperlipidemia & 51.1 & 52.8 & 43.4 & $<.0001$ \\
\hline Thrombolysis after IS, \% & 14.6 & 15.3 & 10.9 & $<.0001$ \\
\hline Interval onset admission, hours, $\%^{\mathrm{a}}$ & & & & $<.0001$ \\
\hline$<=2$ & 20.7 & 21.7 & 15.9 & \\
\hline$>2-3$ & 9.2 & 9.7 & 6.9 & \\
\hline$>3-6$ & 15.3 & 16.0 & 11.9 & \\
\hline$>6-24$ & 16.2 & 17.1 & 12.2 & \\
\hline$>24-48$ & 5.7 & 5.7 & 5.6 & \\
\hline$>48$ & 9.2 & 7.0 & 19.8 & \\
\hline unknown & 23.8 & 22.9 & 27.7 & \\
\hline \multicolumn{5}{|c|}{ Neurological signs within $24 \mathrm{~h}$ after admission, $\%$} \\
\hline Paresis & 55.3 & 55.9 & 52.2 & $<.0001$ \\
\hline Aphasia & 27.5 & 27.4 & 28.2 & 0.0065 \\
\hline Dysarthria & 34.6 & 35.2 & 31.5 & $<.0001$ \\
\hline Disturbed level of consciousness & 9.0 & 6.9 & 18.6 & $<.0001$ \\
\hline \multicolumn{5}{|l|}{ NIHSS on admission, } \\
\hline Median (IQR) & $3(1-7)$ & $3(1-7)$ & $3(1-10)$ & $<.0001$ \\
\hline NIHSS on admission, \% & & & & $<.0001$ \\
\hline$<4$ & 55.5 & 55.6 & 55.1 & \\
\hline $4-15$ & 35.0 & 36.4 & 27.9 & \\
\hline$>15$ & 9.5 & 8.0 & 17.0 & \\
\hline
\end{tabular}


Table 1 Demographic and clinical characteristics of the patients (Continued)

\begin{tabular}{llll}
\hline Day of admission & & & 76.3 \\
Weekday & 73.7 & 73.1 & 23.7 \\
$\quad$ Weekend & 26.3 & 26.9 & \\
Length of stay, days & & & 9.0001 \\
Mean (SD) & $8.8(7.3)$ & $7.7(6.9)$ & $7(4.0)$ \\
Median (IQR) & $7(4-11)$ & $7(4-11)$ & $7(2)$ \\
\hline
\end{tabular}

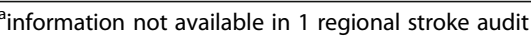

Table 2 Probability for admission of patients with ischemic stroke on a Stroke Unit (demographical and clinical characteristics)

\begin{tabular}{|c|c|c|}
\hline & OR $(95 \% \mathrm{Cl}) n=88,316$ & $P$-values \\
\hline Age categories & & 0.0664 \\
\hline$<65$ & 1 & \\
\hline $65-74$ & $1.03(0.97-1.08)$ & \\
\hline $75-84$ & $1.00(0.95-1.05)$ & \\
\hline$\geq 85$ & $0.95(0.89-1.01)$ & \\
\hline \multicolumn{3}{|l|}{ Sex } \\
\hline Men & 1 & 0.3088 \\
\hline Women & $0.98(0.94-1.02)$ & \\
\hline \multicolumn{3}{|l|}{ Comorbidities } \\
\hline Atrial fibrillation & $1.02(0.98-1.07)$ & 0.2998 \\
\hline Diabetes mellitus & $0.99(0.95-1.03)$ & 0.4659 \\
\hline Hypertension & $1.13(1.08-1.19)$ & $<.0001$ \\
\hline Previous stroke & $0.94(0.90-0.98)$ & 0.0055 \\
\hline Hyperlipidemia & $1.26(1.21-1.31)$ & $<.0001$ \\
\hline \multicolumn{3}{|c|}{ Interval onset admission, hours ${ }^{\mathrm{a}}$} \\
\hline$<=2$ & 1 & $<.0001$ \\
\hline$>2-3$ & $0.94(0.87-1.02)$ & \\
\hline$>3-6$ & $0.88(0.83-0.94)$ & \\
\hline$>6-24$ & $0.90(0.85-0.96)$ & \\
\hline$>24-48$ & $0.61(0.56-0.66)$ & \\
\hline$>48$ & $0.19(0.18-0.20)$ & \\
\hline unknown & $0.43(0.41-0.46)$ & \\
\hline \multicolumn{3}{|l|}{ NIHSS admission } \\
\hline$\leq 3$ & 1 & $<.0001$ \\
\hline$\geq 4-\leq 15$ & $1.30(1.25-1.36)$ & \\
\hline$>15$ & $0.55(0.52-0.59)$ & \\
\hline \multicolumn{3}{|l|}{ Day of admission ${ }^{a}$} \\
\hline weekday & 1 & $<.0001$ \\
\hline weekend & $1.12(1.08-1.17)$ & \\
\hline
\end{tabular}

${ }^{a}$ no information in one regional stroke register indicators were fulfilled in hospitals with a higher proportion of patients being directly admitted to a SU.

Our findings are comparable with previous studies showing that patients treated on a SU tends to be younger on average, had a higher prevalence of comorbidities, especially atrial fibrillation, and hypertension, and were more conscious [3, 17]. Older patients might be more likely to be admitted to a geriatric or general ward, especially older patients with multiple pathologies and greater degrees of frailty [18]. We found a slightly higher probability for patients directly admitted to SUs on weekends. This might be explained by certification requirements of SUs resulting in better staffing of SUs compared to other wards on weekends which could lead to a preferred admission to a SU. Data on quality of care on weekends are heterogeneous. Most studies demonstrate a poorer quality of care, and negative effects for patients being admitted on weekends [18-21], whereas others do not confirm these findings [22-24].

Adherence to given target values of evidence-based QIs was significantly associated with the proportion of patients admitted to a SU. That means, more patients receive guideline-recommended therapy if they are treated on a SU. This implies that ischemic stroke patients should be treated on a SU. But, not all quality indicators are relevant for patients not being treated on a $\mathrm{SU}$ - e.g. patients with intracerebral hemorrhage treated on an Intensive Care Unit. This higher quality of stroke care might be the result of a more specific training of the medical staff of SU (doctors, nurses, and therapists) in acute stroke management. A higher proportion of quality standards met in patients admitted to a SU was also reported by Rudd et al [18]. We found no association between proportion of fulfilled QIs and year of first certification, or the annual number of stroke patients treated. We assume that the quality of stroke care could be maintained even if certification was several years ago. This finding is in contrast to other studies reporting a higher level of quality of care and better outcomes for patients in higher volume SUs [25-27]. Our results suggest that certification requirements of the DSG and the SDSH might ensure quality of SU care independently from the number of patients treated on a local SU per 
Table 3 Achieved Qls by structural factors in hospitals with certified SUs ${ }^{2}$

\begin{tabular}{|c|c|c|c|c|}
\hline & \multicolumn{2}{|c|}{ Hospitals with certified Stroke Units } & \multirow[t]{2}{*}{ Regression coefficient in $\%(95 \%-\mathrm{Cl})^{b}$} & \multirow[t]{2}{*}{$P$-values } \\
\hline & No of hospitals & Mean (SD) \% achieved Qls & & \\
\hline Overall/Intercept & 255 & $93.7(13.3)$ & $86.8(79.4-94.3)$ & \\
\hline \multicolumn{5}{|c|}{ SU admission within hospitals with SU, \% } \\
\hline$<60$ & 16 & $87.6(18.5)$ & 0 & \multirow[t]{3}{*}{0.0002} \\
\hline $60-80$ & 63 & $92.7(14.3)$ & $4.4(1.2-7.5)$ & \\
\hline$>80$ & 176 & $94.4(12.4)$ & $5.7(2.7-8.6)$ & \\
\hline \multicolumn{5}{|c|}{ Year of certification ${ }^{c}$} \\
\hline $2000-2002$ & 31 & $94.2(12.5)$ & 0 & \multirow[t]{4}{*}{0.3014} \\
\hline $2003-2005$ & 42 & $93.3(13.3)$ & $-0.9(-2.6-0.7)$ & \\
\hline $2006-2008$ & 32 & $93.8(14.2)$ & $0.7(-1.3-2.9)$ & \\
\hline 2009-2012 & 81 & $93.6(13.3)$ & $-0.6(-2.1-0.9)$ & \\
\hline \multicolumn{5}{|l|}{ No of patients } \\
\hline$<250$ & 11 & $94.4(12.9)$ & 0 & \multirow[t]{4}{*}{0.7238} \\
\hline $250-500$ & 62 & $92.4(15.1)$ & $1.8(-4.9-8.4)$ & \\
\hline$>500-750$ & 80 & $94.0(13.1)$ & $2.4(-4.1-8.9)$ & \\
\hline$>750$ & 102 & $93.7(13.0)$ & $1.8(-4.7-8.3)$ & \\
\hline
\end{tabular}

${ }^{a} 11$ quality indicators; ${ }^{b}$ analysis adjusted for individual level factors sex, stroke subtype, age, weekday of admission, NIHSS, ' no information about year of certification in one regional stroke register; unknown year of certification of hospitals occurred in every register

year. We found no association between year of certification and number of QI within given target values. There is not much comparable evidence on this subject as previous studies compared certified- and non-certified stroke centers $[28,29]$ or different certification procedures [30]. One strength of the present analyses is the large number of patients analyzed. Data are routinely checked for plausibility, but coding errors at hospital level cannot be ruled out. Because in Germany participation in the ADSR is mandatory only for SUs and in specific regions, we decided not to compare quality of SU care between hospitals with and without SUs, in order to avoid bias due to most an overrepresentation of hospitals with SU care in the dataset and, thus, makes comparisons with centers not providing SU care difficult

Overall from 180,887 stroke patients, $82.4 \%$ were directly admitted to a SU. There seems to be still room for quality improvement regarding the proportion of stroke patients admitted to a SU. Our data contains only information on the admission of a SU. It is possible that patients were transferred from a normal ward to a SU during hospital stay. Unfortunately, this information was not included in our dataset.

The process of admission to a SU might be affected by selection bias as severely affected patients e.g. with intracerebral or subarachnoid hemorrhage are more likely to be admitted to intensive care units or neurosurgical departments. In addition, but unlikely to affect our results relevantly, we might underestimate the entire proportion of patients being treated on a SU, while secondary admissions during the hospital stay were not recorded.

\section{Conclusions}

Our data indicate a high quality of acute SU care in Germany according to predefined quality indicators. The influence of documented structural characteristics on adherence to evidence-based quality indicators was low. However, there might be still room for quality improvement left regarding the proportion of stroke patients admitted to a SU.

\section{Additional file}

Additional file 1: Table S1. Achieved Qls by structural factors in hospitals with certified SUs. Additional analysis to Table 3 of the manuscript. (DOCX $50 \mathrm{~kb}$ )

\section{Abbreviations}

ADSR: German Stroke Register Study Group (Arbeitsgemeinschaft Deutscher Schlaganfall Register); DSG: German Stroke Society (Deutsche Schlaganfall Gesellschaft); GLMM: Generalized linear mixed models; ICH: Intracerebral hemorrhage; IQR: Interquartile range; IS: Ischemic stroke; NIHSS: National Institutes of Health Stroke Scale; QI: Quality indicator; RCTs: Randomized clinical trials; SD: Standard deviation; SDSH: German Stroke Foundation (Stiftung Deutsche Schlaganfall-Hilfe); SU: Stroke unit; TIA: Transient ischemic attack

\section{Acknowledgements}

The authors thank all participating hospitals participating in the regional registers of the ADSR. The following stroke registers participate in the German Stroke Registers Study Group (ADSR). The following stroke registers participate in the German Stroke Registers Study Group (ADSR): Bavaria stroke register: Dr. med. M. Eßer; Baden-Württemberg stroke register: S. Rode; Berlin Stroke Register: Dr. med. B. Hoffmann, Berlin Medical Association, Dr. Georg Walter Vivantes Klinikum am Friedrichshain; Stroke Register Hamburg: R. Hohnhold, EQS-Hamburg Landesgeschäftsstelle Qualitätssicherung [regional office for quality assurance]; Stroke Register Hesse: A. Reihs; Stroke Register of Northwest Germany: M. Kalic; Stroke Register Rhineland-Palatinate: Dr. med. S. 
Dienlin; Stroke Register Schleswig-Holstein: Prof. Dr. med H. Raspe; Erlangen Stroke Register: Prof. Dr. med. P. Kolominsky-Rabas MBA; Technical committee of the ADSR: Dr. med. I. Bruder, Dr. med. S. Dienlin, Dr. med. M. Eßer, Prof. Dr. med. P. Heuschmann, Dr. med. B. Misselwitz, A. Reihs.

\section{Funding}

Parts of the data pooling exercise were financially supported within the framework of the FP7 program by the European Union European Implementation Score collaboration [EIS]; No. 223153. There was no financial or other support by other third parties for the working process or manuscript preparation.

\section{Availability of data and material}

The data that support the findings of this pooled analysis are available upon request from the corresponding author $[\mathrm{SH}]$ after permission by the data holders of the included regional quality assurance projects. The dataset generated and analysed was explicitly pooled for this study upon agreement from each individual regional quality assurance project.

\section{Author's contributions}

SH analysis and interpretation of the data, drafting the manuscript; SW drafting the manuscript; VR analysis of the data; KB, DN, IB, HCK, GS, BM, AJ, $\mathrm{CB}, \mathrm{CM}, \mathrm{OB}$, and $\mathrm{PH}$ data collection and revising the manuscript; $\mathrm{PUH}$ analysis and interpretation of the data, drafting the manuscript. All authors read and approved the final manuscript.

\section{Competing interests}

$S H, V R, D N, I B, B M, A J, C B, C M, O B$, and PH declare that they have no competing interests; SW receives research support from the German Ministry of Research and Education; KB has received within the last 10 years completely investigator-initiated research funding as principal or coordinating investigator in the areas of stroke, depression and subclinical atherosclerosis, multimorbidity and health services research, diabetes, multiple sclerosis and for the German National Cohort from the German Ministry of Research and Technology (BMBF). For the conduction of an investigator initiated clinical register for multiple sclerosis he has received a grant from the German Competence Net Multiple Sclerosis with funds from Biogen Idec. For the conduction (2007-2014) of a study on the course of Restless Legs Syndrome he has received unrestricted grants to the University of Muenster from the German Restless Legs Society and Boehringer Ingelheim Pharma, Mundipharma Research, Neurobiotec, Roche Pharma, UCB Germany, UCB Switzerland and Vifor Pharma; HCK serves as an auditor in the certification process of stroke units and is a member of the certification committee of the DSG; GS reports unrestricted education grants from Bayer Health Care, Biotronic, Boehringer Ingelheim, Biogen Idec, Bracco, Bristol-Myers Squibb, Grifols, Pfizer, Philips, Genzyme, Merck Serono, Noras, Novartis, Takeda, Teva, UCB, HOCOMA, Braun, Shire, Talecris, Sanofi Aventis, MSD, Meda, Desitin, Krauth + Timmermann; PUH reports grants from the European Union (within EIS) during study conduct; from the German Ministry of Research and Education, Charité, Berlin Chamber of Physicians, German Parkinson Society, University Hospital Würzburg, Robert-Koch-Institute, Charité-Universitätsmedizin Berlin (within MonDAFIS; MonDAFIS is supported by an unrestricted research grant to the Charité from Bayer), University Göttingen (within FIND-

AFrandomized; FIND-AFrandomized is supported by an unrestricted research grant to the University Göttingen from Boehringer-Ingelheim), and University Hospital Heidelberg (within RASUNOA-prime; RASUNOA-prime is supported by an unrestricted research grant to the University Hospital Heidelberg from Bayer, BMS, Boehringer-Ingelheim, Daiichi Sankyo), outside submitted work.

\section{Consent for publication}

The identity of the individual patients was completely anonymous. Therefore, no specific informed consent was obtained by patients.

\section{Ethics approval and consent to participate}

The data pooling was approved by the ethics committee of the ChariteUniversitätsmedizin Berlin (EA4/043/10) and is registered by the University of Würzburg (214/11). The identity of the individual patients was completely anonymous. Therefore, no specific informed consent was obtained by patients. The investigators who performed the data analyzes were blinded to hospital identities. These identities are only known by the coordinating center of the respective regional stroke registers.

\section{Author details}

Institute of Clinical Epidemiology and Biometry (ICE-B) Würzburg, Josef-Schneider-Str. 2 / D7, 97080 Würzburg, Germany. ${ }^{2}$ Comprehensive Heart Failure Center, University of Würzburg, Straubmühlweg 2a, 97078 Würzburg, Germany. ${ }^{3}$ Quality Assurance Project"Stroke Register Northwest Germany", Institute of Epidemiology and Social Medicine, University of Münster, Albert-Schweitzer-Campus 1, Gebäude D3, 48149 Münster, Germany. ${ }^{4}$ Department of Neurology, Vivantes Klinikum Neukölln, Berlin, Rudower Straße 48, 12351 Berlin, Germany. ${ }^{5}$ Office for Quality Assurance in Hospitals (GeQiK) Stuttgart at Baden-Wuerttembergische Hospital Federation, Stuttgart, Birkenwaldstr. 151, 70191 Stuttgart, Germany. ${ }^{6}$ Vivantes Klinikum im Friedrichshain, Berlin, Landsberger Allee 49, 10249 Berlin, Germany. ${ }^{7}$ Department of Neurology, Asklepios Klinik Nord, Hamburg," Tangstedter Landstraße 400, 22417 Hamburg, Germany. Institute of Quality Assurance Hesse (GQH), Frankfurter Str. 10, 65760 Eschborn, Germany. ${ }^{9}$ Quality Assurance in Stroke Management in North Rhine-Westphalia, Medical Association North Rhine, Tersteegenstr. 9, 40474 Düsseldorf, Germany. ${ }^{10}$ Institute of Quality Assurance Rhineland-Palatinate / SQMed, Wilhelm-Theodor-Römheld-Straße 34, 55130 Mainz, Germany. ${ }^{11}$ Quality Association for Acute Stroke Treatment Schleswig-Holstein (QugSS), Institute of Social Medicine and Epidemiology, University of Lübeck, Ratzeburger Allee 160, 23538 Lübeck, Germany. ${ }^{12}$ German Stroke Society, Berlin, Reinhardtstr. 27C, 10117 Berlin, Germany. ${ }^{13}$ Bavarian Permanent Working Party for Quality Assurance, Munich, Westenriederstr. 19, 80331 Munich, Germany. ${ }^{14}$ Clinical Trial Center Würzburg, University Hospital Würzburg, Josef-Schneider-Str. 2 / D7, 97080 Würzburg, Germany.

\section{Received: 10 October 2016 Accepted: 10 February 2017 Published online: 09 March 2017}

\section{References}

1. Stroke Unit Trialists' Collaboration. Organised inpatient (stroke unit) care for stroke. Cochrane Database Syst Rev 2013; 9:CD000197. Epub 2013/09/13.

2. Bray BD, Ayis S, Campbell J, Hoffman A, Roughton M, Tyrrell PJ, et al. Associations between the organisation of stroke services, process of care, and mortality in England: prospective cohort study. BMJ. 2013;346:f2827.

3. Langhorne P, Lewsey JD, Jhund PS, Gillies M, Chalmers JW, Redpath A, et al. Estimating the impact of stroke unit care in a whole population: an epidemiological study using routine data. J Neurol Neurosurg Psychiatry. 2010;81(12):1301-5.

4. Turner M, Barber M, Dodds H, Dennis M, Langhorne P, Macleod MJ. The impact of stroke unit care on outcome in a Scottish stroke population, taking into account case mix and selection bias. J Neurol Neurosurg Psychiatry. 2015;86(3):314-8.

5. Walter A, Seidel G, Thie A, Raspe H. Semi-intensive stroke unit versus conventional care in acute ischemic stroke or TIA - a prospective study in Germany. J Neurol Sci. 2009;287(1-2):131-7.

6. Wiedmann S, Heuschmann PUH, Hill MD. Organized stroke care: Germany and Canada. In: Norrving B, editor. Oxford Textbook of Stroke and Cerebrovascular Disease. 1st ed. New York, NY: Oxford University Press; 2014. p. 270-8.

7. Nabavi DG, Ossenbrink M, Schinkel M, Koennecke HC, Hamann G, Busse O Revised certification criteria for regional and national stroke units in Germany. Nervenarzt. 2015;86:978-88.

8. LGA InterCert GmbH. Stroke Units Zertifizierung. Landesgewerbeanstalt (LGA) TÜV Rheinland web page. http://www.lga-intercert.com/branchen/ medizin-und-gesundheitswesen/stroke-units-zertifizierung/. Accessed 26 Sept 2016.

9. Krogias C, Bartig D, Kitzrow M, Weber R, Eyding J. Trends of hospitalized acute stroke care in Germany from clinical trials to bedside. Comparison of nation-wide administrative data 2008-2012. J Neurol Sci. 2014;345(1-2):202-8.

10. Scholten N, Pfaff H, Lehmann HC, Fink GR, Karbach U. Thrombolysis for acute stroke-a nationwide analysis of regional medical care. Fortschr Neurol Psychiatr. 2013:81(10):579-85.

11. Heuschmann PU, Berger K. International experience in stroke registries: German Stroke Registers Study Group. Am J Prev Med. 2006:31(6 Suppl 2):S238.

12. Wiedmann S, Heuschmann PU, Hillmann S, Busse O, Wietholter H, Walter GM, et al. The quality of acute stroke care- an analysis of evidence-based indicators in 260000 patients. Dtsch Arztebl Int. 2014;111(45):759-65. 
13. Nabavi DG, Ringelstein EB, Faiss J, Kessler C, Rother J, Busse O. Regional and national stroke units in Germany: amended certification criteria. Nervenarzt. 2012;83(8):1039-52.

14. Ringelstein EB, Busse O, Ritter MA. Current concepts of Stroke Units in Germany and Europe. Schweiz Arch Neurol Psychiatr. 2011;162(4):155-60.

15. Heuschmann PU, Busse O, Wagner M, Endres M, Villringer A, Rother J, et al. Frequency and Care of Stroke in Germany. Aktuelle Neurol. 2010;37(7):333-40.

16. Baird AE, Dambrosia J, Janket S, Eichbaum Q, Chaves C, Silver B, et al. A three-item scale for the early prediction of stroke recovery. Lancet. 2001; 357(9274):2095-9.

17. Candelise L, Gattinoni M, Bersano A, Micieli G, Sterzi R, Morabito A. Strokeunit care for acute stroke patients: an observational follow-up study. Lancet. 2007;369(9558):299-305.

18. Rudd AG, Hoffman A, Down C, Pearson M, Lowe D. Access to stroke care in England, Wales and Northern Ireland: the effect of age, gender and weekend admission. Age Ageing. 2007;36(3):247-55.

19. McKinney JS, Deng Y, Kasner SE, Kostis JB. Comprehensive stroke centers overcome the weekend versus weekday gap in stroke treatment and mortality. Stroke. 2011;42(9):2403-9.

20. Palmer WL, Bottle A, Davie C, Vincent CA, Aylin P. Dying for the weekend: a retrospective cohort study on the association between day of hospital presentation and the quality and safety of stroke care. Arch Neurol. 2012; 69(10):1296-302.

21. Campbell JT, Bray BD, Hoffman AM, Kavanagh SJ, Rudd AG, Tyrrell PJ. The effect of out of hours presentation with acute stroke on processes of care and outcomes: analysis of data from the Stroke Improvement National Audit Programme (SINAP). PLoS One. 2014;9(2):e87946.

22. Albright KC, Savitz SI, Raman R, Martin-Schild S, Broderick J, Ernstrom K, et al. Comprehensive stroke centers and the 'weekend effect': the SPOTRIAS experience. Cerebrovasc Dis. 2012;34(5-6):424-9.

23. Albright K, Hallevi H, Raman R, Ernstrom K, Martin-Schild S, Meyer B, et al. Can comprehensive stroke centers erase the "Weekend effect"? Neurology. 2008;70(11):A18-A18

24. Kim SC, Hong KS, Hwang SI, Kim JE, Kim AR, Cho JY, et al. Weekend admission in patients with acute ischemic stroke is not associated with poor functional outcome than weekday admission. J Clin Neurol. 2012;8(4):265-70.

25. Schwamm LH, Fonarow GC, Reeves MJ, Pan W, Frankel MR, Smith EE, et al. Get With the Guidelines-Stroke is associated with sustained improvement in care for patients hospitalized with acute stroke or transient ischemic attack. Circulation. 2009;119(1):107-15.

26. Svendsen ML, Ehlers LH, Ingeman A, Johnsen SP. Higher stroke unit volume associated with improved quality of early stroke care and reduced length of stay. Stroke. 2012;43(11):3041-5.

27. Reeves MJ, Gargano J, Maier KS, Broderick JP, Frankel M, Labresh KA, et al. Patient-Level and Hospital-Level Determinants of the Quality of Acute Stroke Care. A Multilevel Modeling Approach. Stroke. 2010; Epub 2010/10/23.

28. Johnson AM, Goldstein LB, Bennett P, O'Brien EC, Rosamond WD. Compliance with acute stroke care quality measures in hospitals with and without primary stroke center certification: the North Carolina Stroke Care Collaborative. J Am Heart Assoc. 2014;3(2):e000423.

29. Stradling D, Yu W, Langdorf ML, Tsai F, Kostanian V, Hasso AN, et al. Stroke care delivery before vs after JCAHO stroke center certification. Neurology. 2007;68(6):469-70

30. Fonarow GC, Liang L, Smith EE, Reeves MJ, Saver JL, Xian Y, et al. Comparison of performance achievement award recognition with primary stroke center certification for acute ischemic stroke care. J Am Heart Assoc 2013:2(5):e000451.

\section{Submit your next manuscript to BioMed Central and we will help you at every step:}

- We accept pre-submission inquiries

- Our selector tool helps you to find the most relevant journal

- We provide round the clock customer support

- Convenient online submission

- Thorough peer review

- Inclusion in PubMed and all major indexing services

- Maximum visibility for your research

Submit your manuscript at www.biomedcentral.com/submit

CBiomed Central 